\title{
Cheek Hematoma: A Rare Presentation
}

\author{
${ }^{1}$ Niveditha J Sagar, ${ }^{2}$ Chidananda Ramappa Devasamudra
}

\section{ABSTRACT}

Background: A 28-year-old lady presented with cheek hematoma on the right side after the self-fall. This patient had severe facial disfigurement due to diffuse swelling of cheek, discoloration of facial skin and sclera. The facial expressions were also compromised.

Materials and methods: Detailed history taken, examination done to rule out motor vehicle accident (MVA), domestic violence and central nervous system (CNS) involvement. Computed tomography scan was done to know the extent of hematoma and to rule out the oromaxillofacial bone fractures. Incision and drainage was done to remove the blood clot from the buccal space. Incision was given in the buccal mucosa to avoid external scar.

Result: Swelling was completely reduced on 3rd postoperative day. Facial movements and expressions were regained.

Conclusion: Intraoral Incision and drainage is the treatment of choice for cheek hematoma to reduce the size of the swelling and avoid external scar.

Keywords: Hematoma, Incision and drainage, External scar.

How to cite this article: Sagar NJ, Devasamudra CR. Cheek Hematoma: A Rare Presentation. Panam J Trauma Crit Care Emerg Surg 2015;4(1):39-42.

\section{Source of support: Nil}

Conflict of interest: None

\section{RESUMEN}

Antecedentes: Una señora de 28 años de edad se presentó con la mejilla. Hematoma en el lado derecho después de la auto-otoño. Este paciente tenía. desfiguración facial severa debido a difundir hinchazón de la mejilla, decoloración de la piel facial y la esclerótica. Las expresiones faciales también fueron comprometida.

Materiales y métodos: La historia tomada detallada, examen hecho para descartar accidente de vehículo de motor (MVA), nacional la violencia y el sistema restringido central (SNC). Tomografía computarizada se realizó para conocer el

\footnotetext{
${ }^{1,2}$ Assistant Professor

1,2Department of Otorhinolaryngology, Sapthagiri Institute of Medical Sciences and Research Center, Bengaluru, Karnataka India

Corresponding Author: Niveditha J Sagar, Assistant Professor, Department of Otorhinolaryngology, Sapthagiri Institute of Medical Sciences and Research Center, Bengaluru Karnataka, India, Phone: 8971491130, e-mail: niveditha150@ gmail.com
}

alcance de hematoma y para descartar las fracturas óseas oromaxillofacial. Incisión y drenaje se realiza para eliminar el coágulo de sangre de el espacio bucal. Incisión fue dado en la mucosa bucal para evitar la cicatriz externa.

Resultado: La hinchazón se reduce por completo el 3 de postoperatorio día. Movimientos y expresiones faciales se recuperaron.

Conclusión: Intraoral incisión y el drenaje es el tratamiento de opción para hematoma mejilla para reducir el tamaño de la hinchazón y evitar cicatriz externa.

Palabras claves: Hematoma, Incisión y drenaje, La cicatriz externa.

\section{INTRODUCTION}

This article focuses on facial soft-tissue trauma. No other part of the body is as conspicuous, unique and esthetically significant as the face. Because an individual's self-image and self-esteem are often derived from his or her own facial appearance. Any injury affecting these features requires particular attention.

Patients with traumatic facial injuries often present with extremely disfigured appearances. Each patient who presents with significant traumatic facial injuries should be treated in accordance with American Trauma Life Support (ATLS) protocols. Once immediately life-threatening issues, such as airway compromise and uncontrolled bleeding have been addressed, other multisystem trauma is excluded. Attention can then be turned to defining and definitively treating the patient's facial injuries.

We present a 28-year-old lady with cheek hematoma on right side after the self-fall. Intraoral incision and drainage were done to reduce the size of cheek hematoma and avoid ugly external scar.

\section{CASE REPORT}

A 28-year-old female patient came with history of self fall and injury over the right side of the mandible. She had severe facial disfigurement due to the cheek swelling and discoloration of the facial skin. She walked into our outpatient department (OPD) 2 days after the trauma. Detailed history was taken. She developed unilateral cheek swelling, darkish discoloration of upper lip, buccal mucosa, periorbital area and sclera on the right side followed by trauma to the face. As per the patient history, patient fell down and the hard object hit the body of the mandible on the right side. There was no history of road

Paper presented in research competition in the PTS Congress, Panama, 2014. 
traffic accident, assault or domestic violence. No history of unconsciousness or vomiting after the trauma (to rule out CNS involvement). No history of similar complaints in the past. No history suggestive of bleeding tendency and no history of drug intake (like heparin or aspirin) which alters the coagulation profile.

On examination, a diffuse swelling was present over the right cheek extending superiorly involving the both upper and lower eye lids, compromising eye opening and facial movements (Fig. 1). The swelling involves right half of the upper lip anteriorly. Swelling involves preauricular area posteriorly and inferiorly swelling was extending toward submandibular area. Darkish brown discoloration was noted over the periocular region, around the angle of the mouth, mucosa of upper lip and the buccal mucosa on the right side. On ocular examination, vision, fundus and mobility of eye ball were normal. But, the reddish discoloration was noted over the lateral part of sclera on right side. On bimanual examination, the swelling was tender on touch, soft to cystic in consistency.

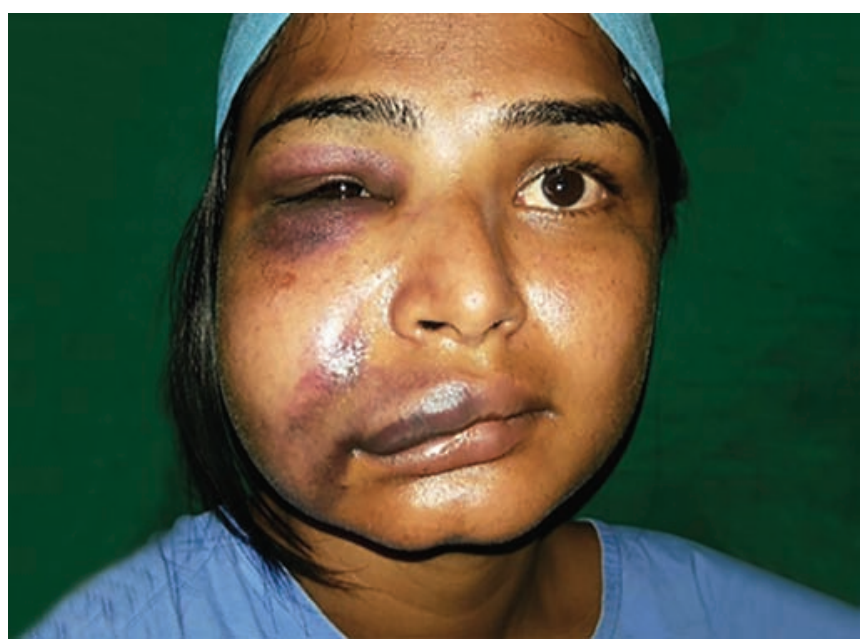

Fig. 1: Diffuse swelling of the right side of the face, darkish brown discoloration of periorbital area, upper lip, angle of the mouth and cheek

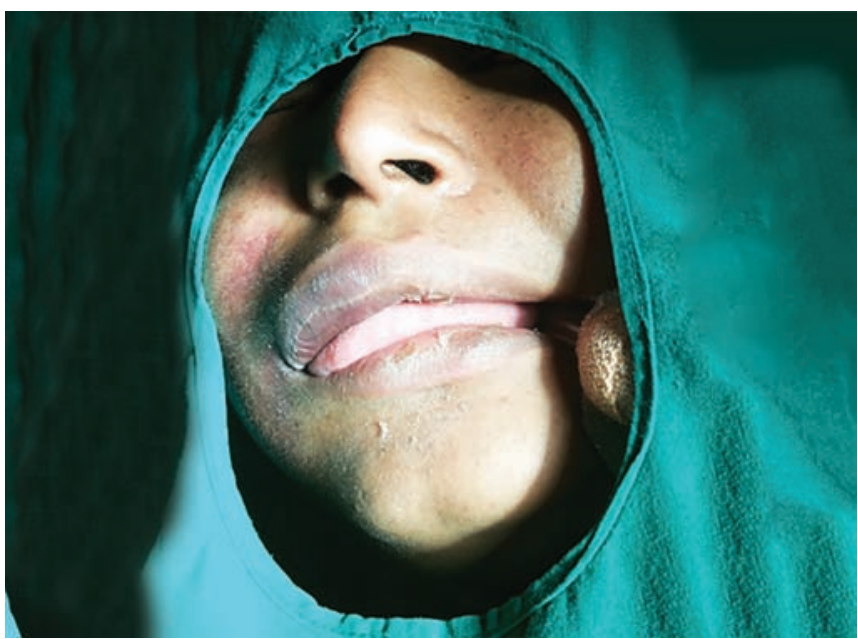

Fig. 3: Endotracheal intubation, tube is on the left side
She underwent routine and special investigation to know the general condition of the patient, to rule out bleeding disorders and to confirm the diagnosis. Complete hemogram, PT, aPTT platelet count were normal. Computed tomography (CT) scan exposing face, orbit and oromaxillofacial area done and we could not see any bone fracture and displacements. But, we could see the hypodense lesion in the buccal space on the right side suggestive of liquid collection (Fig. 2).

This patient was posted for incision and drainage under general anesthesia on the day of presentation, as an emergency case. Requested anesthetist to place the oral endotracheal tube on the left side (Fig. 3) and keep the throat pack. Doyen's mouth gag is used to open the oral cavity (Fig. 4). A $1 \mathrm{~cm}$ horizontal incision was given at the level of upper 1st premolar tooth on the right side (Fig. 5). By doing this, we are going to preserve the stenson's duct, the buccal branch of facial nerve and there will not be any external scar. With the blunt artery forceps, the incision wound was widened to enter the buccal space.

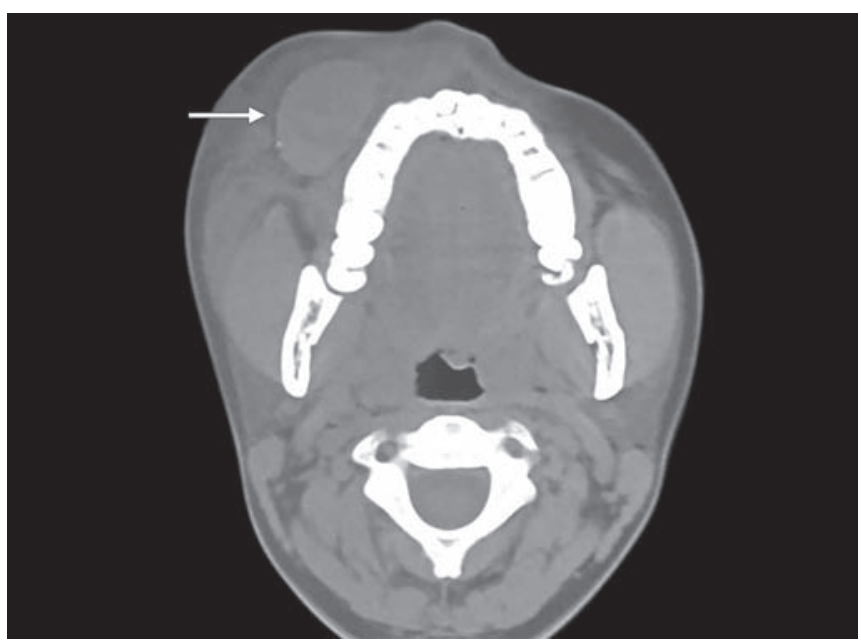

Fig. 2: Hypodense lesion in the buccal space on the right side suggestive of liquid collection

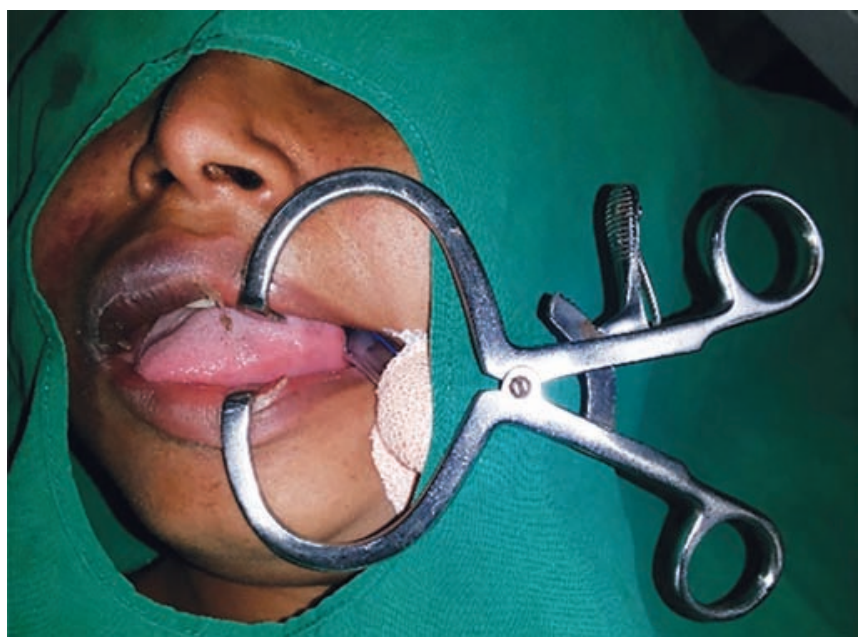

Fig. 4: Doyen's mouth gag used to open the mouth 


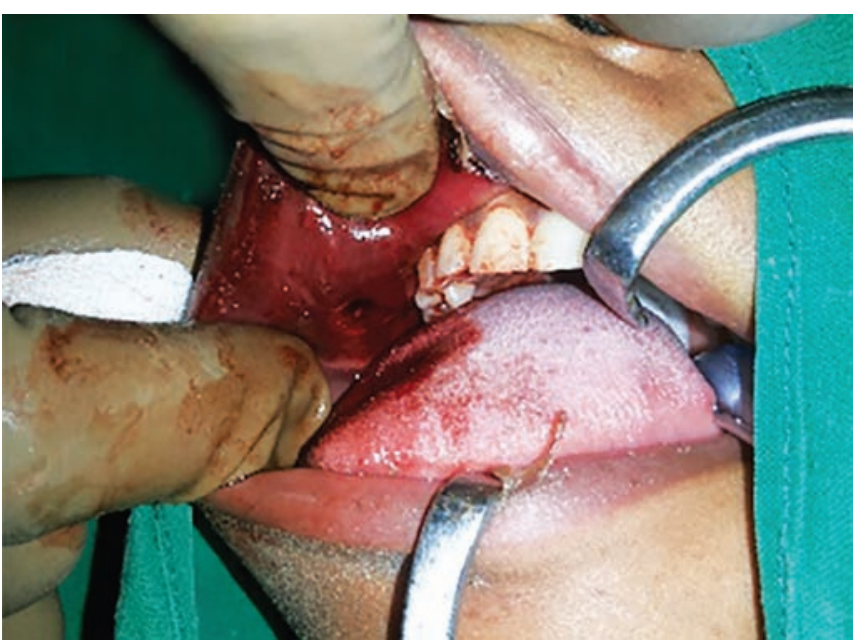

Fig. 5: Intraoral incision at the level of upper 1st premolar tooth

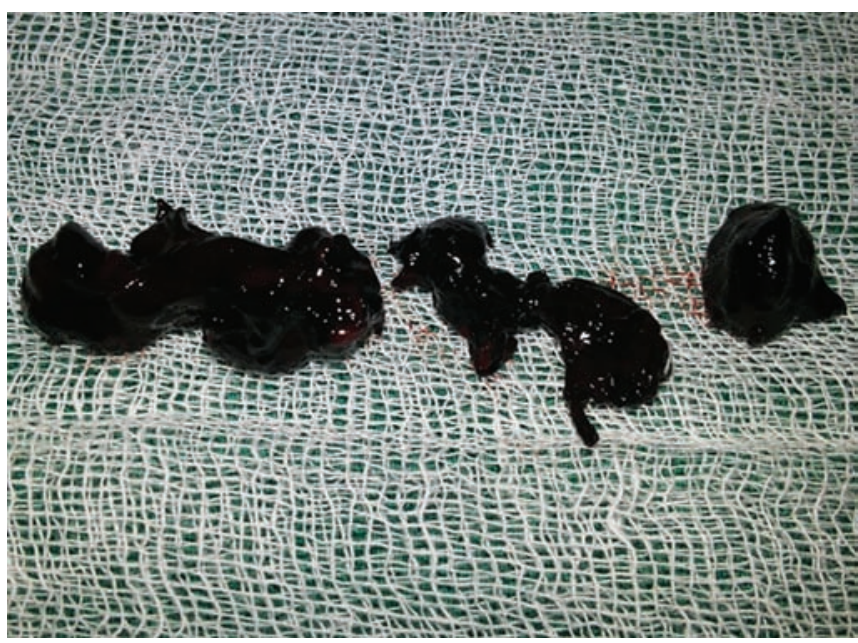

Fig. 7: Blood clot specimen

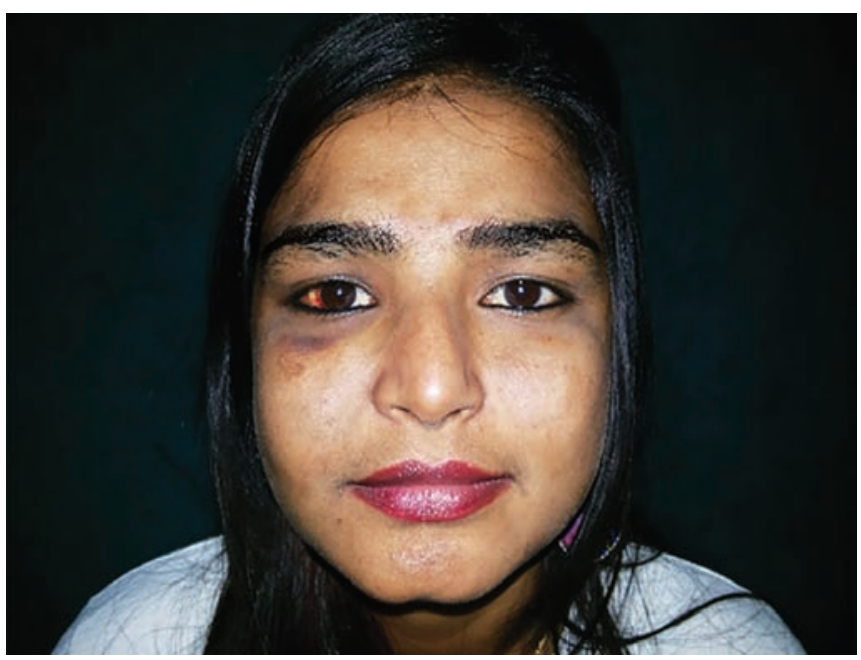

Fig. 9: Postoperative picture after 3 weeks

The darkish brown blood clots propped out through the incision (Fig. 6). The blood clots were removed by compressing the cheek over the bony prominences (Fig. 7). Blood clots in the upper lip were also removed by pressing the lip against the teeth. There was no fresh active bleeding so, the incised wound was sutured with

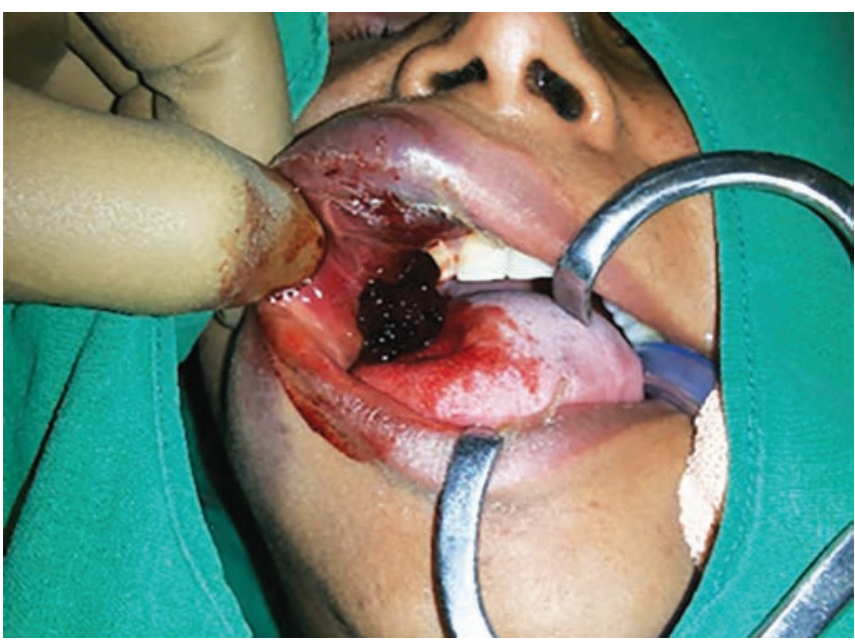

Fig. 6: Blood clot propping out through the incision

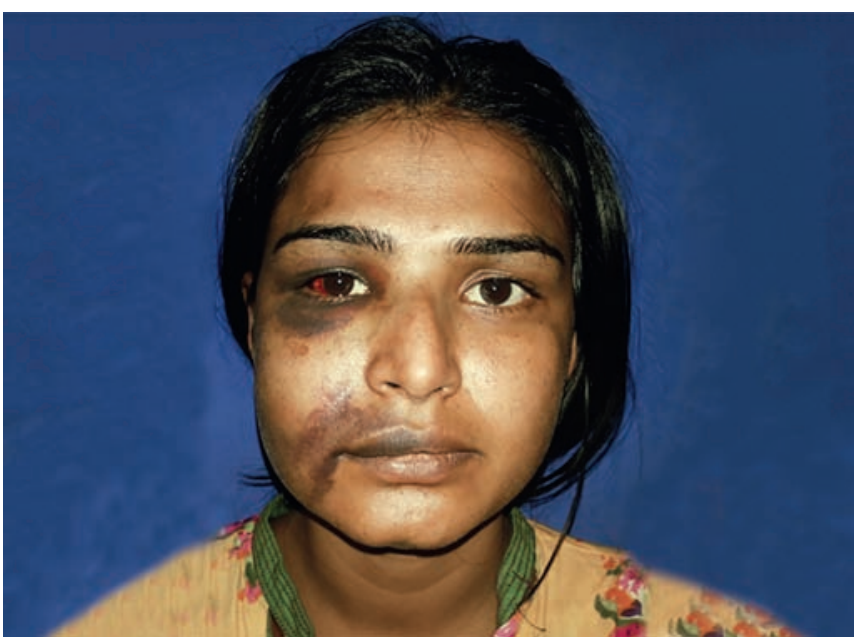

Fig. 8: Postoperative picture on 3rd day, swelling has reduced

3-0 vicryl. Intravenous injection dexamethasone $4 \mathrm{mg}$ was given twice daily for 3 days.

Diffuse swelling was almost reduced on 3rd postoperative day (Fig. 8). After 3 weeks, patient came to our OPD for regular follow-up visit and she was happy with the results. There was no swelling, facial expressions were normal and there was limited discoloration of facial skin (Fig. 9).

\section{Etiopathogenesis}

In this case, patient gave history of self-fall and trauma to the body of the mandible on the right side. Patient noticed shooting pain in the right side of the face soon after the injury. Immediately, patient developed cheek swelling. According to the site of injury, the facial artery would have ruptured and leading to hematoma and cheek swelling.

The facial artery arises in the carotid triangle from the external carotid artery a little above the lingual artery and, sheltered by the ramus of the mandible, passes obliquely up beneath the digastric and stylohyoid muscles, over which it arches to enter a groove on the posterior surface of the submandibular gland. ${ }^{1}$ 
It, then, curves upward over the body of the mandible at the anteroinferior angle of the masseter; passes forward and upward across the cheek to the angle of the mouth, then ascends along the side of the nose, and ends at the medial commissure of the eye, under the name of the angular artery.

The facial artery is remarkably tortuous. This is to accommodate itself to neck movements, such as those of the pharynx in deglutition; and facial movements, such as those of the mandible, lips and cheeks. ${ }^{1}$

\section{DISCUSSION}

A hematoma is a common complication of facial softtissue trauma. A large, expanding hematoma can result in necrosis of the overlying skin ${ }^{2,3}$ or adjacent subcutaneous fat, increased incidence of infection, scarring, skin hyperpigmentation, tissue edema and a prolonged convalescence.

Historically, severe facial trauma often resulted in cosmetic and functional defects; however, advances in the science of reconstructive surgery and in the management of trauma patients have significantly improved the morbidity associated with facial traumatic injuries. In the most extreme cases, facial transplantation has even been accomplished at a number of centers throughout the world. ${ }^{4,5}$

Motor vehicle accidents (MVAs) were the most frequent cause of facial injuries, however, other factors like on-the-job accidents, sports-related injuries, domestic interpersonal violence, self-inflicted wounds and animal bites are also attributable for facial injuries. ${ }^{6-10}$

Address the most life-threatening problems first. Evaluate the patient's facial injuries only after establishing a definitive airway, stabilizing hemodynamics, and assessing other associated life-threatening injuries.

The prognosis for most facial soft-tissue injuries is good; the injuries usually heal rapidly, allowing the patient to return to usual activities. Facial soft-tissue injury complications include, but are not limited to infection, hematoma, flap or wound-edge necrosis, nasal septum necrosis, parotid duct laceration, retained foreign body, poor cosmesis, permanent deformity (e.g. cauliflower ear) and loss of function related to nerve injury or scarring.

Systematically examine the face by means of visual inspection and palpation, starting superiorly with the scalp and the frontal bones and proceeding inferiorly and laterally. Inspect and note any obvious swellings, depressions or ecchymosis. With palpation, determine the presence and location of any fractured bone fragments and dislodged or dislocated bony prominences; be sure to include the temporomandibular joint. Determining the presence of crepitus, tenderness or step off is essential.
Computed tomography, however, has greater sensitivity in defining bony facial trauma. Any patient with a bony step off or instability, periorbital swelling or contusion, Glasgow Coma Scale score less than 14, malocclusion, or tooth absence is at high risk for an associated facial fracture and CT scanning is warranted. ${ }^{11}$

Although patients with traumatic facial injuries often present with extremely disfigured appearances, their injuries are seldom life-threatening. Treat each patient who presents with significant traumatic facial injuries as a trauma patient in accordance with ATLS protocol.

\section{CONCLUSION}

Multidisciplinary approach is a must to take care of Facial trauma and head injury cases. Neurosurgeon, ophthalmologist, oromaxillofacial surgeon, intensivist and ENT surgeon are included in the trauma team. Establish the airway, stabilize the hemodynamics and rule out life-threatening limb, spine, thoracic, abdomen and CNS injuries. And then, facial injuries are evaluated by CT scan. Soft-tissue injuries like cheek, hematoma, can be managed by intraoral incision and drainage to avoid external scar and injury to vital structures of the cheek.

\section{REFERENCES}

1. The complete 20th US edition of Gray's anatomy of the human body, published in 1918.

2. Oliver DW, Inglefield CJ. Liposuction of haematoma. Br J Plast Surg 2002;55:269-270.

3. Dowden RV, Bergfeld JA, Lucas AR. Aspiration of hematomas with liposuction apparatus: a technical note. J Bone Joint Surg Am 1990;72:1534-1535.

4. Gordon CR, Siemionow M, Papay F, et al. The world's experience with facial transplantation: what have we learned thus far? Ann Plast Surg 2009 Nov;63(5):572-578.

5. Alam DS, Chi JJ. Facial transplantation for massive traumatic injuries. Otolaryngol Clin North Am 2013 Oct;46(5):883-901.

6. Echlin PS, Upshur RE, Peck DM, Skopelja EN. Craniomaxillofacial injury in sport: a review of prevention research. Br J Sports Med 2005 May;39(5):254-263.

7. Massimiliano B, Nicola S, Sante B, Carmela F, Palmieri V, Paolo Z. Female boxing in Italy: 2002-2007 report. Br J Sports Med 2011 Jun;45(7):563-570.

8. Lawson BR, Comstock RD, Smith GA. Baseball-related injuries to children treated in hospital emergency departments in the United States, 1994-2006. Pediat 2009 Jun;123(6):e1028-1234.

9. Day C, Stolz U, Mehan TJ, Smith GA, McKenzie LB. Divingrelated injuries in children $<20$ years old treated in emergency departments in the United States: 1990-2006. Pediat 2008 Aug;122(2):e388-394.

10. Rajput D, Bariar LM. Study of maxillofacial trauma, its aetiology, distribution, specturm and management. J Ind Med Assoc 2013 Jan;111(1):18-20.

11. Sitzman TJ, Hanson SE, Alsheik NH, Gentry LR, Doyle JF, Gutowski KA. Clinical criteria for obtaining maxillofacial computed tomographic scans in trauma patients. Plast Reconstr Surg 2011 Mar;127(3):1270-1278. 